\title{
Sistemas de Custos: importância, viabilidade e utilidade na concepção dos agentes públicos do Estado do Paraná (Brasil)
}

\begin{abstract}
Resumo
Este estudo tem por objetivo conhecer o nível de entendimento e de adoção quanto aos sistemas de custos por parte dos municípios do Paraná. Trata-se de estudo descritivo, com abordagem qualitativa. A coleta de dados ocorreu mediante aplicação de um questionário em 67 municípios do Estado do Paraná. Executou-se análise descritiva e aplicouse o teste estatístico de correlação do coeficiente de Spearman para fins de atender o objetivo. Dentre os resultados do estudo, destacam-se: a incipiência do conhecimento acerca da importância, viabilidade e utilidade de um sistema de custos; embasado por limitações no conhecimento por parte dos agentes públicos, sobretudo, nos tópicos que tratam de viabilidade orçamentária e financeira da adoção de sistemas de custos; ambiente para o sistema de custos, sistemas de custos implantados e sistemas operacionais; embora as respostas obtidas nas proposições sobre informação e controle de custos tenham sido significativamente coerentes.
\end{abstract}

Palavras-chave: Sistema de Custos. Contabilidade de Custos. Setor Público.

\begin{abstract}
Luciane Maria Gonçalves Franco Mestre em Contabilidade (UFPR), Doutoranda em Gestão Urbana (PUCPR), Analista de Controle Externo no Tribunal de Contas do Estado do Paraná. Contato: Praça Nossa Senhora da Salete, $\mathrm{s} / \mathrm{n}^{\circ}$, Centro Cívico, Curitiba, PR, Brasil, CEP: 80530-912. E-mail: lutc@tce.pr.gov.br
\end{abstract}

Cristiano do Nascimento Mestre em Contabilidade (UFPR) E-mail: cristiano.nascimento.cont@gmail.com

\section{Márcia Maria dos Santos Bortolocci Espejo}

Doutora em Controladoria e Contabilidade (FEA/USP), Professora e Coordenadora na Universidade Federal do Paraná (UFPR). Contato: Av. Pref. Lothário Meissner, 632, Jardim Botânico,Curitiba, PR, Brasil, CEP: 80210-170.

E-mail:marciabortolocci@ufpr.br

\section{Simone Bernardes Voese}

Doutora em Engenharia de Produção (UFSC), Professora e Coordenadora na Universidade Federal do Paraná (UFPR). Contato: Av. Pref. Lothário Meissner, 632, Jardim Botânico, Curitiba, PR, Brasil, CEP: 80210-170. E-mail: simone.voese@gmail.com 


\section{Introdução}

A gestão pública brasileira, a exemplo de diversos países desenvolvidos, tem passado por diversas reformas (Di Giácomo, 2005), que visam a promover a superação dos modelos burocráticos e incorporar técnicas gerenciais e noções de qualidade, produtividade, resultados factíveis e responsabilidade (Pereira, 1998). Os primeiros países a aderirem à reforma gerencial do Estado foram o Reino Unido, a Austrália e a Nova Zelândia (Dias, Gondrige, Clamente, Espejo \& Voese, 2009). “The New Public Management” foi um termo cunhado na década de 80 para designar "A Nova Gestão Pública”, que buscava incorporar experiências do setor privado, mediante esforços de profissionalização na prestação de serviços públicos e o estabelecimento de doutrinas por vezes ligadas ao racionalismo econômico (Hood, 1989).

Não foram poucas as emendas constitucionais, leis e normativas nas últimas décadas que deram respaldo à implantação do Plano Diretor da Reforma do Estado, no governo Fernando Henrique Cardoso (Pereira, 1998). Destarte, reservou a si objetivos como a redução da máquina administrativa estatal e a descentralização das ações de governo, munindo o Estado de ferramentas eficazes de controle e de tomada de decisões, aplicadas aos setores de orçamento, contabilidade, finanças, patrimônio e controle interno. Essas inovações contribuíram com a necessidade de os gestores conhecerem os custos das entidades públicas, com a finalidade de decidir entre as alternativas de produzir, comprar, terceirizar ou privatizar.

Decorrente da obrigatoriedade legal na adoção de sistemas de custos, bem como que este representa importante instrumento de controle e tomada de decisão, o presente estudo é orientado pela seguinte questão de pesquisa: qual o nível de entendimento e adoção por parte dos municípios do Estado do Paraná em termos de importância, viabilidade e utilidade do sistema de custos? Outras percepções decorrerão das respostas obtidas dos agentes públicos, as quais são indicadas no resultado do estudo.

Nessa concepção, os objetivos da presente pesquisa são: conhecer o nível de entendimento e de adoção quanto aos sistemas de custos por parte dos municípios do Paraná, e, de forma específica, consoante as respostas do survey aplicado, analisar o nível de dificuldades de implantação percebidas, o grau de conhecimento acerca de sistemas de custos por parte desses profissionais e as noções de condições estruturais e financeiras.

O estudo justifica-se pelo fato de identificar o nível de entendimento e de adoção dos sistemas de custos por parte dos profissionais municipais, já que esses instrumentos podem tornar-se importante ferramenta de controle nas atividades de governo, garantir o alcance dos objetivos orçados e, por conseguinte, o cumprimento da missão institucional. Outro fator relevante é a avaliação da noção, por parte dos agentes municipais, da disponibilidade de recursos financeiros e estruturais para custear a implantação de novos sistemas, que pode ser elemento norteador à busca de recursos internos e/ou externos ao cumprimento da demanda. De outra parte, verifica-se que ainda são incipientes os estudos que avaliem a adoção de sistemas de custos públicos no Brasil, à medida que inexistem indicativos científicos dessa natureza, para o Estado do Paraná.

O Paraná está situado na Região Sul do país, em posição geográfica estratégica, ao fazer fronteira com importantes centros econômicos como o Estado de São Paulo, os países Paraguai e Argentina. Também caracteriza o corredor de ligação com os demais estados da região sul, Santa Catarina e Rio Grande do Sul; ocupa uma área de $199.880 \mathrm{~km}^{2}$ e a economia paranaense é a quinta maior do país. O estado responde atualmente por 6\% do Produto Interno Bruto (PIB) nacional e registra a renda per capita de $\mathrm{R} \$ 21,1$ mil em 2010, acima do valor de R $\$ 19,3$ mil referente ao Brasil (Instituto Paranaense de Desenvolvimento Econômico e Social, Ipardes, 2010).

O presente artigo está estruturado em cinco seções, além desta: (i) referencial teórico composto de indicações literárias no tocante à modernização da contabilidade pública brasileira, obrigatoriedade da implantação dos sistemas de custos públicos e sistemas contábeis para o setor público paranaense, (ii) metodologia que subsume tipologia da pesquisa, população e amostras, coleta de dados e procedimentos estatísticos aplicados, (iv) resultados do estudo, (iv) considerações finais, encerramento com as (v) Referências consultadas. 


\section{Referencial Teórico}

O referencial teórico, revisão de literatura, marco teórico ou theorical arguments, ou ainda theoretical background, para Boaventura (2004), objetiva revisar ou "demonstrar o que já foi escrito sobre o tema. Consiste na análise e síntese de informações, visando definir as linhas de ação para abordar o problema e gerar ideias novas e úteis".

\subsection{Modernização da administração pública brasileira}

A administração pública brasileira, a exemplo do que vem ocorrendo a partir dos anos $80 \mathrm{em}$ diversos países, como Austrália, Inglaterra, Estados Unidos, Nova Zelândia, Japão, Itália, Canadá, Espanha, Suécia, Suíça, Argentina, Turquia, Áustria, México, Irlanda, Portugal, Coreia do Sul, Finlândia, tem passado por diversas reformas conjunturais (Di Giácomo, 2005), que visam a promover a "superação dos modelos burocráticos do passado, de forma a incorporar técnicas gerenciais que introduzam na cultura do trabalho público noções indispensáveis de qualidade, produtividade, resultados e responsabilidade dos funcionários" (Pereira, 1998, p. 28).

Essa nova concepção de gestão pública alcançou referência em estudos acadêmicos sob o título de "The New Public Management (NPM)", designada, no Brasil, como a Nova Gestão Pública, conceito este que desde as suas menções preliminares nos trabalhos de Hood (1995) busca uma conjugação de experiências e técnicas gerenciais entre o setor público e o privado. O referido autor expõe, sumariamente, como principais características da NPM: a desagregação das organizações em entes a serem geridos separadamente, a busca de maior concorrência entre as organizações do setor público e do privado, a utilização de práticas de gestão comuns às empresas; maior disciplina no uso dos recursos e na busca de alternativas de desonerar a prestação de serviços e a adoção de medidas de desempenho e de controle (Hood, 1995, p. 95).

Assim, a nova versão de gestão pública passa a conceber a administração consoante um modelo profissional e técnico que se preste a dar atendimento às demandas da sociedade por um serviço público efetivo, de acordo com os direitos e as expectativas do contribuinte. Nessa esteira, a profissionalização deve intensificar o desenvolvimento econômico e, ao mesmo tempo, manter a capacidade política de governar em nome do povo, garantindo, contudo o comprometimento da competência administrativa e financeira para implementar políticas públicas e sem dar lugar à "nobreza burocrática e prebendária" (Di Giácomo, 2005).

No Brasil, a década de 90 foi marcada por diversas reformas originadas das Emendas Constitucionais de números 01 a 24, a maioria, relacionada a assuntos afetos ao setor público. A experiência foi iniciada, em 1995, com a implantação do Plano Diretor da Reforma do Aparelho do Estado, que teve por objetivos gerenciais a redução da máquina administrativa estatal e a descentralização das ações de governo, sem, no entanto, perder o foco de função eminentemente pública em prol do cidadão contribuinte (Dias et al., 2009). Uma série de medidas foi desencadeada em todos os estados e municípios brasileiros, visando profissionalizar a gestão pública, munindo-a de ferramentas gerenciais eficazes para fins de controle e tomadas de decisões, diretamente ligadas aos setores de orçamento, contabilidade, finanças, patrimônio e controle interno.

Notadamente, a administração governamental possui características distintas daquelas reservadas à iniciativa privada, e, nesse contexto, cumpre destacar o aparato restritivo que o princípio da legalidade impõe aos gestores, ou seja, na Administração Pública só é permitido fazer o que a lei autoriza, enquanto que na particular é lícito fazer tudo o que a lei não proíbe (Meirelles, 2009). Dessa forma, a implantação de sistemas contábeis e de custos deixa de ser uma faculdade ao gestor, para tornar-se obrigação cujo descumprimento pode acarretar responsabilização à pessoa do gestor e/ou à entidade pública. 


\subsection{Obrigatoriedade legal e normativa de implantação de sistemas de custos públicos}

No ano de 2000, foi editada a Lei Complementar Federal n. ${ }^{\circ}$ 101/2000, a Lei de Responsabilidade Fiscal (LRF), revolucionária na instituição de limitadores ao endividamento público e ao controle de gastos com pessoal, além de firmar critérios de responsabilização com o vértice de assegurar o equilíbrio planejado das contas públicas. O texto da Lei incorpora o conceito de custos, que, desde 1964, fora consagrado na contabilidade pública, mediante a previsão do Art. 85, da Lei Federal n. ${ }^{\circ}$ 4.320/64:

Os serviços de contabilidade serão organizados de forma a permitirem o acompanhamento da execução orçamentária, o conhecimento da composição patrimonial, a determinação dos custos dos serviços industriais, o levantamento dos balanços gerais, a análise e a interpretação dos resultados econômicos e financeiros. (LF № 4320/64) [sem grifo no original]

Sendo assim, a LRF traz nova conotação ao antigo preceito de gestão pública: a necessidade da implantação de sistemas de custos por parte de todas as entidades governamentais brasileiras. O Art. $4^{\circ}$, da LRF ainda impõe à Lei de Diretrizes Orçamentárias (LDO) a devida instrumentalização de termos norteadores à efetiva implantação dos sistemas de custos públicos, em atendimento às normas constitucionais:

Art. $4^{\circ}$ A lei de diretrizes orçamentárias atenderá o disposto no $\$ 2^{\circ}$ do art. 165 da Constituição e:

I - disporá também sobre:

(...)

e) normas relativas ao controle de custos e à avaliação dos resultados dos programas financiados com recursos dos orçamentos; (LC No 101/2000 - LRF) [sem grifo no original]

Ademais, também o Art. 50 da LRF prevê que a escrituração de contas públicas deverá observar, entre outros aspectos, a necessidade de manutenção permanente de sistemas de custos que possibilitem a avaliação e o acompanhamento da gestão orçamentária, financeira e patrimonial por parte dos gestores públicos, por exemplo, custos do sistema de saúde, custos do setor de educação, custos administrativos, custos por programas, custos de cobrança e execução de dívida. Outros dispositivos, como o Art. 14 da LRF, disciplinam o controle de custos como medida acessória imprescindível ao cumprimento de imposições legais, por exemplo, o controle de renúncia de receitas e da concessão de benefício e natureza tributária.

Art. 50. Além de obedecer às demais normas de contabilidade pública, a escrituração das contas públicas observará as seguintes: (...)

\$3 A Administração Pública manterá sistema de custos que permita a avaliação e o acompanhamento da gestão orçamentária, financeira e patrimonial. (LC No 101/2000 - LRF) [sem grifo no original]

Art. 14. A concessão ou ampliação de incentivo ou benefício de natureza tributária da qual decorra renúncia de receita deverá estar acompanhada de estimativa do impacto orçamentário-financeiro no exercício em que deva iniciar sua vigência e nos dois seguintes, atender ao disposto na lei de diretrizes orçamentárias e a pelo menos uma das seguintes condições:

(...)

$\$ 3^{\mathrm{o}} \mathrm{O}$ disposto neste artigo não se aplica:

(...)

II - ao cancelamento de débito cujo montante seja inferior ao dos respectivos custos de cobrança. (LC No $101 / 2000$ - LRF) [sem grifo no original]

Outro marco relevante ocorreu em 2008, quando o Ministério da Fazenda (MF) editou a Portaria n. ${ }^{\circ}$ 184/08 e determinou à Secretaria do Tesouro Nacional (STN) a promoção da convergência das nor- 
mas de contabilidade pública às Normas Internacionais de Contabilidade publicadas pela International Federation of Accountants (IFAC) e às Normas Brasileiras aplicadas ao Setor Público editadas pelo Conselho Federal de Contabilidade (CFC), pelo fato de considerar a adoção de boas rotinas contábeis como fator de credibilidade da informação e instrumento de acompanhamento e comparação econômico-financeira e do desempenho dos entes públicos, além de franquear economicidade e eficiência na alocação de recursos (Portaria n. ${ }^{\circ}$ 184/2008).

No Brasil, por meio de esforços conjuntos entre organismos profissionais, governamentais e por pesquisadores das Ciências Contábeis, essa convergência está sendo efetivada no ano de 2010. A autorização ministerial provocou uma gama de estudos por todo o País e culminou na edição, por parte do Conselho Federal de Contabilidade (CFC), de dez Normas Brasileiras de Contabilidade aplicadas ao Setor Público (NBCASP), numeradas de 16.1 a 16.10. Dentre essas normas, cita-se a NBCASP n. ${ }^{\circ} 16.2$, referendada pela Resolução n. ${ }^{\circ}$ 1.129/2008-CFC, intitulada Patrimônio e os Sistemas Contábeis, cujo teor prescreve, entre outros aspectos, a implantação de sistemas de custos, como modalidade do subsistema do contábil.

12. O sistema contábil está estruturado nos seguintes subsistemas de informações:

(a) Orçamentário - registra, processa e evidencia os atos e os fatos relacionados ao planejamento e à execução orçamentária;

(b) Financeiro - registra, processa e evidencia os fatos relacionados aos ingressos e aos desembolsos financeiros, bem como as disponibilidades no início e final do período;

(c) Patrimonial - registra, processa e evidencia os fatos não financeiros relacionados com as variações qualitativas e quantitativas do patrimônio público;

(d) Custos - registra, processa e evidencia os custos dos bens e serviços, produzidos e ofertados à sociedade pela entidade pública;

(e) Compensação - registra, processa e evidencia os atos de gestão cujos efeitos possam produzir modificações no patrimônio da entidade do setor público, bem como aqueles com funções específicas de controle. (CFC, NBCASP 16.2) [sem grifo no original]

A NBCASP 16.2 estabelece ainda que os respectivos subsistemas contábeis devem ser integrados entre si e a outros sistemas eletrônicos operacionais e de informações, de modo a auxiliar a administração pública no cumprimento da sua missão institucional, relativamente à avaliação dos resultados obtidos na execução dos programas, com foco na preservação de princípios como a economicidade, a eficiência, a eficácia e a efetividade, para permitir, também, avaliação das metas planejadas e orçadas, bem como a análise dos riscos e das contingências a que se sujeitam os entes públicos.

\subsection{O Estado do Paraná e seus municípios}

O presente estudo está voltado aos municípios do Estado do Paraná, economicamente, uma das importantes unidades da Federação, com suas 399 cidades, e cuja capital é Curitiba. O estado é o quinto a possuir maior número de municípios, atrás de Minas Gerais, com suas 853 cidades, que se segue de São Paulo, com 645, do Rio Grande do Sul, com 496 municípios e do Estado da Bahia, que registra, atualmente, 417 cidades. O Paraná está entre os oito estados brasileiros que concentra 80\% do PIB nacional, juntamente com São Paulo, Rio de Janeiro, Minas Gerais, Rio Grande do Sul, Bahia, Santa Catarina e Distrito Federal e, nesse sentido, têm relevância o centro industrial na região metropolitana de Curitiba, os portos marítimos de Paranaguá e Antonina, bem como o turismo da região oeste, representado na cidade fronteiriça de Foz do Iguaçu. O estado está dividido em 10 mesorregiões, quais sejam: Metropolitana de Curitiba, Centro Ocidental Paranaense, Centro Oriental Paranaense, Centro-Sul Paranaense, Noroeste Paranaense, Norte Central Paranaense, Norte Pioneiro Paranaense, Oeste Paranaense, Sudeste Paranaense e Sudoeste Paranaense (Ipardes, 2010). 
Esses sinais fazem com que o conjunto de municipalidades paranaenses desperte a atenção por parte de pesquisadores, dada a importância econômica que exerce, evidenciada nos balanços públicos e nos indicadores sociais e econômicos, seja por suas riquezas físicas e geográficas, seja pelo grau de expansão de seus negócios. De outra parte, a concentração de renda gera, ao mesmo tempo, a necessidade de controles hábeis para que os gestores administrativos possam garantir o desempenho que a sociedade espera, no tocante aos serviços e obras públicas.

\subsection{Sistemas Contábeis para o setor público municipal do Paraná}

Desde o exercício financeiro de 2001, quando do advento da Lei de Responsabilidade Fiscal, o Estado do Paraná tem implementado procedimentos eletrônicos para a fiscalização das contas públicas municipais. Essas medidas acabaram por impor modernização aos setores contábeis de todos os municípios paranaenses, vez que a prestação de contas, de entrega obrigatória consoante prescrição constitucional, passou a ser realizada somente pela via eletrônica, de sistemas criados e fornecidos diretamente pelo órgão fiscalizador, o Tribunal de Contas do Estado do Paraná. O principal sistema, no âmbito municipal, foi denominado Sistema de Informações Municipais (SIM).

O SIM foi oficialmente instituído pelo Provimento n. ${ }^{\circ} 46 / 2001$ do Tribunal de Contas do Estado do Paraná (TCE-PR), com a finalidade de racionalização de informações, para fins de controle externo, para recepcionar a remessa de dados necessários à composição da prestação de contas. O seu principal objetivo é dar celeridade à apreciação das contas e auxiliar no acompanhamento da gestão orçamentária, contábil, financeira, patrimonial e operacional dos Municípios e deve ser utilizado pelos Poderes Legislativo e Executivo, inclusive as autarquias, fundações, consórcios intermunicipais e sociedades do Poder Público Municipal. Aos dados do SIM, orienta-se o devido respaldo em registros contábeis, em conformidade com as Normas Brasileiras de Contabilidade do CFC, respondendo o agente pela sua fidelidade e exatidão (TCE-PR, 2001).

Os sistemas eletrônicos criados no Paraná constituem, portanto, elemento fundamental para a convergência da contabilidade pública aos padrões internacionais, observando que a informatização está no cerne da modernização contábil, sem a qual se torna impossível a implantação dos sistemas dos custos previstos na legislação e na NBCASP 16.2. Consoante essa norma, verifica-se que, havendo, os municípios do Estado do Paraná, implantado moderno sistema eletrônico contábil, resta aberto o caminho a futuras adaptações, seja de cunho cultural ou estrutural, seja para a implementação dos sistemas de custos públicos.

\subsection{Funções da Contabilidade de Custos no setor público}

A modernização do setor público inseriu em seu contexto inovações que contribuíram com a necessidade de que os gestores públicos conheçam os custos parciais e totais de suas entidades, com a finalidade de tomar as melhores decisões entre as alternativas de produzir, comprar, terceirizar ou privatizar. Para tanto, conceitua-se custo como todo sacrifício (consumo) de ativos para a obtenção de produtos ou serviços (Slomski, 2006). O referido autor entende que os principais métodos de custeio podem ser utilizados com sucesso pelas entidades públicas, ou seja, pode ser aplicado o Método de Custeio por Absorção; ou o de Custeio Variável ou Direto; ou Custeio Baseado em Atividades, bem ainda o método de Custeio Padrão, na mensuração de seus custos.

$\mathrm{Na}$ administração pública, um sistema de custos representa instrumento fundamental a ser usado para averiguar os resultados e avaliar a gestão dos recursos, no que tange à eficácia e à eficiência dos serviços produzidos, das obras realizadas e dos programas de governo (Dias et al, 2009) .

Martins (2003, p. 21) aponta duas funções relevantes à contabilidade de custos: auxílio ao controle e tomadas de decisões. Para o autor, no que diz respeito ao controle, a "sua mais importante missão é for- 
necer dados para o estabelecimento de padrões, orçamentos e outras formas de previsão" e, em um estágio seguinte, subsidiar o acompanhamento das ações. No que tange às decisões, "consiste na alimentação de informações sobre valores relevantes" a serem gerenciados.

O sistema contábil, conforme Silva (2007), deve fornecer informações para determinados objetivos, entre os quais o planejamento e controle de custos das operações e atividades, mediante a criação de relatórios sobre custos e ativos por unidades gestoras, por centro de custos aos gestores. Para o (IFAC, 2000) apud Dias et al. (2009), as informações de custos podem suprir diversas necessidades gerenciais na administração pública, destacando-se as seis funções sociais para a contabilidade de custos, conforme a Figura 1.

\begin{tabular}{|ll|}
\hline \multicolumn{1}{|c|}{ Função Social } & \multicolumn{1}{c|}{ Necessidades Gerenciais } \\
\hline Orçamento & $\begin{array}{l}\text { As informações de custos podem auxiliar a decisão de alocação de recursos entre } \\
\text { várias atividades. Os custos das atividades passadas podem ser utilizados como } \\
\text { estimativas orçamentárias de custos futuros. }\end{array}$ \\
\hline Redução e Controle de Custos & $\begin{array}{l}\text { A análise do comportamento dos custos pode auxiliar na tomada de ações } \\
\text { apropriadas para eliminar ineficiências. }\end{array}$ \\
\hline Ajuste de Preços e Tarifas & $\begin{array}{l}\text { Auxiliam no estabelecimento de cenários de preços e tarifas para bens e serviços } \\
\text { fornecidos pelo governo, especialmente quando esses são fornecidos a um preço } \\
\text { inferior ao custo, como um resultado de políticas governamentais. }\end{array}$ \\
\hline Avaliação de Desempenho & $\begin{array}{l}\text { Pode auxiliar a mensuração do desempenho financeiro e não financeiro. Os esforços } \\
\text { e os resultados dos serviços de uma entidade podem ser avaliados com as seguintes } \\
\text { mensurações: custos dos recursos e insumos usados para fornecer os serviços e o } \\
\text { resultado alcançado. }\end{array}$ \\
\hline Avaliação de Programas & $\begin{array}{l}\text { As informaçães de custos podem auxiliar nas decisões políticas relacionadas à } \\
\text { autorização, modificação e descontinuidade desses. }\end{array}$ \\
\hline Outras Decisões Econômicas & $\begin{array}{l}\text { A escolha entre as alternativas de ações requer comparação de custo ou receitas } \\
\text { incrementais, como, por exemplo, decisões de privatização, aceitar ou rejeitar uma } \\
\text { proposta de projeto governamental, continuar ou descontinuar um produto ou serviço. }\end{array}$ \\
\hline
\end{tabular}

Figura 1. Necessidades gerenciais da administração pública.

Fonte: Dias et al. (2009).

Wiemer e Ribeiro (2004) defendem a relevância da apuração dos custos em vista da necessidade do controle social, pois a apuração e a publicidade de custos propiciam a usuários e auditores informações sobre a qualidade dos serviços prestados. Aduzem os autos que, pela inexistência de sistema de custos, esse controle fica centrado somente em aspectos formais e legais dos atos de gestão.

Para Rezende, Cunha e Cardoso (2010), a importância das informações sobre os custos do governo não se resume à contribuição que elas podem dar para a eficiência e a eficácia do gasto público, mas também pelo que representa à luz da necessidade de ser promovida uma profunda reforma da gestão pública no País, indispensável para que o Poder Público possa responder adequadamente aos desafios contemporâneos que se apresentam à sociedade brasileira.

Cumpre mencionar que a informação de custos pode viabilizar uma série melhorias tanto para a administração pública quanto para o cidadão usuário dos serviços e obras públicas, no Brasil e no mundo, como revelam as pesquisas de Costa, Santos, Rodrigues, Barreto e Roberts (2005), que estimaram os custos da tuberculose para o sistema de saúde de Salvador; de Turner, Woolley e Kingsleyl (2007), que estimaram os custos da construção de casas populares nos Estados Unidos; e de Sonfield, Host, Gold e Finer (2011), que reuniram os custos da gravidez indesejada para os programas de seguros públicos de Nova Iorque.

Constata-se, portanto, que os sistemas de custos, que sempre representaram instrumento fundamental às tomadas de decisões na iniciativa privada, passam agora a figurar como elemento obrigatório na gestão responsável dos recursos públicos. 


\section{Metodologia}

Este estudo emprega os métodos de natureza descritiva no intuito de alcançar o objetivo proposto, qual seja conhecer o nível de entendimento e de adoção quanto aos sistemas de custos por parte dos municípios do Paraná. Este estudo caracteriza-se com objetivo descritivo porque com ele busca-se descrever o comportamento dos fenômenos ou características da população-alvo, mensura e ou quantifica os eventos (Cooper e Schindler, 2003).

O método de coleta de dados fundamenta-se no procedimento interrogação/comunicação, mediante estudo ex post facto em que não se altera ou manipula o conjunto de dados obtidos dos respondentes. $\mathrm{O}$ estudo é transversal por representar um instantâneo de um determinado momento. A abordagem é qualitativa, pois, inclusive, é lida com o viés da subjetividade nas respostas da survey (Cooper e Schindler, 2003).

Em termos de amplitude e profundidade submetem-se os dados ao tratamento estatístico, inicialmente à análise descritiva e, em seguida, à técnica de correlação do coeficiente de Spearman, cujo modelo permite avaliar os dados para comprovar se uma proposição é explicada por outra (Cooper e Schindler, 2003). Para se acatar ou rejeitar as proposições investigadas, adota-se o nível de significância de 0,05 e 0,01. O coeficiente de correlação de Spearman é uma estatística não paramétrica, o qual classifica os dados em primeiro lugar e depois aplica a equação de Pearson (Field, 2009). Para o tratamento estatístico, utilizou-se o software SPSS - Statistical Package for the Social Sciences, versão 17.

A elaboração deste estudo parte da revisão de literatura, consulta a documentos e normatização vigente acerca de controle de custos e sistemas de custos. Desenvolveu-se formulário com proposições diretas, para as quais foram colhidas as percepções por parte dos agentes públicos, estas, dispostas em escala do tipo Likert de cinco pontos, para as seguintes opções de respostas: (1) discordo plenamente, (2) discordo, (3) indeciso, (4) concordo e (5) concordo plenamente.

A população compreende o total de municípios do Estado do Paraná, em número de 399, coletados de controladores, contadores e ou servidores ligados aos setores contábeis municipais. Para cada município, foi remetido um formulário para ser preenchido (survey). A amostra foi definida pelo número de formulários que retornaram preenchidos, ou seja, no total de 67 municípios que passaram a compor a amostra, durante o exercício financeiro de 2010.

\section{Resultados do Estudo}

O tema pesquisado encontra-se subdividido em tópicos. Deste modo, facilita-se o entendimento das proposições submetidas ao agente público. A referida subdivisão em tópicos também permite o detalhamento na análise dos dados coletados, a saber: 1- importância da informação de custos; 2 - viabilidade orçamentária e financeira da adoção de sistemas de custos; 3 - competência da informação de custos; 4 - ambiente para o sistema de custos; 5 - sistemas de custos implantados; e 6 - sistemas operacionais.

\subsection{Análise descritiva dos dados}

Os resultados da pesquisa são submetidos à análise descritiva dos dados, os quais expressam o posicionamento assumido pelo agente público em relação a cada proposição, cujos resultados são apresentados em termos percentuais. No tópico 1, investigam-se aspectos relacionados à importância da informação de custos. Nesse contexto, aborda-se a divulgação interna, controle de custos e adoção de sistema de custos. Na Tabela 1, expõe-se a percepção dos agentes públicos consultados. 
Tabela 1

\section{Concepções sobre a importância da informação de custos}

\begin{tabular}{|c|c|c|c|c|c|}
\hline Proposições do tópico 1 & $\begin{array}{c}\text { discordo } \\
\text { plenamente (\%) }\end{array}$ & $\begin{array}{l}\text { discordo } \\
(\%)\end{array}$ & $\begin{array}{l}\text { indeciso } \\
(\%)\end{array}$ & $\begin{array}{l}\text { concordo } \\
(\%)\end{array}$ & $\begin{array}{c}\text { concordo } \\
\text { plenamente (\%) }\end{array}$ \\
\hline $\begin{array}{l}1.1 \text { Existe divulgação de informações } \\
\text { internas, quanto à necessidade de } \\
\text { controles de custos. }\end{array}$ & 40,3 & 13,4 & 10,4 & 34,4 & 1,5 \\
\hline $\begin{array}{l}1.2 \text { É comum na instituição discussões } \\
\text { acerca de custos de serviços ou de } \\
\text { sistemas de custos. }\end{array}$ & 46,2 & 23,9 & 7,5 & 13,4 & 9 \\
\hline $\begin{array}{l}1.3 \text { A instituição adota algum tipo } \\
\text { de controle de custos para o setor } \\
\text { administrativo. }\end{array}$ & 4,5 & 25,4 & 10,4 & 55,2 & 4,5 \\
\hline $\begin{array}{l}1.4 \text { A instituição adota algum tipo de } \\
\text { controle de custos para o setor de } \\
\text { educação. }\end{array}$ & 11,9 & 13,4 & 3 & 65,7 & 6 \\
\hline $\begin{array}{l}1.5 \text { A instituição adota algum tipo de } \\
\text { controle de custos para o setor de saúde. }\end{array}$ & 4,5 & 19,4 & 1,5 & 58,2 & 16,4 \\
\hline $\begin{array}{l}1.6 \text { A instituição adota algum tipo de } \\
\text { controle de custos para o setor de obras. }\end{array}$ & 10,4 & 26,9 & 17,9 & 34,4 & 10,4 \\
\hline $\begin{array}{l}\text { 1.7 A instituição adota algum tipo de } \\
\text { controle de custos para outros setores não } \\
\text { identificados nas frases } 1.3 ; 1.4 ; 1.5 ; 1.6 \\
\text { listadas anteriormente. }\end{array}$ & 35,8 & 49,2 & 7,5 & 1,5 & 6 \\
\hline $\begin{array}{l}\text { 1.8 Considero importante o esforço da } \\
\text { administração para a adoção de sistemas } \\
\text { custos. }\end{array}$ & 1,5 & 0 & 3 & 19,4 & 76,1 \\
\hline
\end{tabular}

Fonte: Dados da pesquisa empírica.

Conforme dados expostos na Tabela 1, os agentes públicos consultados acerca da importância da informação de custos mostram-se discordantes, em 53,7\% quanto à existência de divulgação de informações internas com foco no controle de custos, e 70,1\% aponta discordância de discussões sobre custos de serviços ou de sistemas de custos. Portanto, nas proposições 1.1 e 1.2, constata-se reduzida divulgação interna sobre controle de custos e sobre sistemas de custos, na perspectiva dos entrevistados.

Os apontamentos feitos nas proposições $1.3 ; 1.4 ; 1.5$; e 1.6, indicam posicionamento favorável na adoção de algum controle de custos nos setores administrativos; educação; saúde; e de obras. Para 95,5 $\%$ dos entrevistados, considera-se importante o esforço da administração para a adoção de sistemas de custos, e isto corrobora no intento de fundamentar a importância da informação de custos no ambiente de gestão pública.

No tópico 2, reportam-se os aspectos relacionados à viabilidade orçamentária e financeira da adoção de sistemas de custos, com foco no ano de implantação do referido sistema. Na Tabela 2, apresenta-se a classificação das ponderações feitas pelos agentes públicos. 
Tabela 2

Concepção acerca da viabilidade orçamentária e financeira da adoção de sistemas de custos

\begin{tabular}{|c|c|c|c|c|c|}
\hline Proposições do tópico 2 & $\begin{array}{c}\text { discordo } \\
\text { plenamente (\%) }\end{array}$ & $\begin{array}{c}\text { discordo } \\
(\%)\end{array}$ & $\begin{array}{c}\text { indeciso } \\
(\%)\end{array}$ & $\begin{array}{c}\text { concordo } \\
(\%)\end{array}$ & $\begin{array}{c}\text { concordo } \\
\text { plenamente (\%) }\end{array}$ \\
\hline $\begin{array}{l}\text { 2.1 Considera-se que há viabilidade } \\
\text { orçamentária e financeira para a } \\
\text { implantação de sistemas de custos no } \\
\text { próximo exercício. }\end{array}$ & 1,5 & 4,5 & 14,9 & 53,7 & 25,4 \\
\hline $\begin{array}{l}\text { 2.2 Considera-se que há viabilidade } \\
\text { orçamentária e financeira para a } \\
\text { implantação de sistemas de custos no } \\
\text { exercício de } 2012 \text {. }\end{array}$ & 1,5 & 1,5 & 10,5 & 49,2 & 37,3 \\
\hline $\begin{array}{l}\text { 2.3 Considera-se que há viabilidade } \\
\text { orçamentária e financeira para a } \\
\text { implantação de sistemas de custos após o } \\
\text { ano de } 2012 \text {. }\end{array}$ & 6 & 1,5 & 44,7 & 7,5 & 40,3 \\
\hline
\end{tabular}

Fonte: Dados da pesquisa empírica.

O resultado identificado, mediante Tabela 2, permite inferir sobre a ausência de viabilidade orçamentária e financeira para a adoção de sistemas de custos no ano em que se aplica a pesquisa, a saber, ano de 2010. Embora um percentual significativo de agentes públicos considere a possibilidade de se implantar o sistema de custos em 2011 e ou 2012, destaca-se o nível de indecisão em 44,7\% em relação à implantação após o ano de 2012. Logo, tende-se a aceitar o fato de que os agentes públicos desconhecem as reais condições municipais acerca da viabilidade orçamentária e financeira referente à adoção de sistemas de custos.

O tópico 3 trata da concepção acerca da competência da informação de custos. Nesse contexto, investigam-se aspectos relacionados a custos de projetos e atividades, conhecimento sobre normativa de custos para o setor público, capacitação de servidores e sistemas operacionais, conforme apresentado na Tabela 3.

Tabela 3

Concepções sob re a competência da informação de custos

\begin{tabular}{|c|c|c|c|c|c|}
\hline Proposições do tópico 3 & $\begin{array}{c}\text { discordo } \\
\text { plenamente (\%) }\end{array}$ & $\begin{array}{c}\text { discordo } \\
(\%)\end{array}$ & $\begin{array}{c}\text { indeciso } \\
(\%)\end{array}$ & $\begin{array}{c}\text { concordo } \\
(\%)\end{array}$ & $\begin{array}{c}\text { concordo } \\
\text { plenamente (\%) }\end{array}$ \\
\hline $\begin{array}{l}3.1 \text { A Instituição conhece os fatores que } \\
\text { influenciam o custo de seus projetos e } \\
\text { atividades. }\end{array}$ & 19,4 & 13,4 & 61,2 & 3 & 3 \\
\hline $\begin{array}{l}3.2 \text { Há profissional que conhece as } \\
\text { normativas de custos para o setor público. }\end{array}$ & 35,8 & 7,5 & 3 & 49,2 & 4,5 \\
\hline $\begin{array}{l}\text { 3.3 Há capacitação de servidores em } \\
\text { termos de sistemas de custos. }\end{array}$ & 40,3 & 28,4 & 1,5 & 16,4 & 13,4 \\
\hline $\begin{array}{l}\text { 3.4 Há sistemas operacionais instalados } \\
\text { preparados para adoção de subsistemas } \\
\text { de custos. }\end{array}$ & 9 & 0 & 26,9 & 59,6 & 4,5 \\
\hline $\begin{array}{l}3.5 \text { Há profissional especializado em } \\
\text { custos. }\end{array}$ & 17,9 & 16,4 & 37,3 & 20,9 & 7,5 \\
\hline $\begin{array}{l}3.6 \text { Há corpo técnico especializado em } \\
\text { custos. }\end{array}$ & 35,8 & 22,4 & 28,4 & 13,4 & 0 \\
\hline
\end{tabular}

Fonte: Dados da pesquisa empírica. 
A partir dos dados dispostos na Tabela 3, destaca-se a proposição 3.1, na qual 61,2\% declaram indecisão quanto ao fato de a instituição conhecer os fatores que influenciam os custos de projetos e atividades. Constata-se que 53,7\% concordam com a existência de profissionais que conhecem as normativas de custos para o setor público, e que $64,1 \%$ concordam com a existência de sistemas operacionais instalados preparados para adoção de subsistemas de custos. Mas os dados apontam para a discordância em relação à capacitação do agente público e apenas 7,5\% dos respondentes concordam que há profissional especializado em custos.

No tópico 4, investiga-se a concepção dos agentes públicos em relação ao ambiente para o sistema de custos. Nesse tópico, busca-se identificar a intenção de gestores, servidores e legisladores diante da perspectiva de adoção do sistema de custos, assim como da prefeitura e o cronograma da implantação. Na Tabela 4, demonstra-se a classificação das ponderações feitas pelos agentes públicos.

Tabela 4

\section{Concepções sobre o ambiente para o sistema de custos}

\begin{tabular}{|c|c|c|c|c|c|}
\hline Proposições do tópico 4 & $\begin{array}{c}\text { discordo } \\
\text { plenamente (\%) }\end{array}$ & $\begin{array}{l}\text { discordo } \\
(\%)\end{array}$ & $\begin{array}{l}\text { indeciso } \\
(\%)\end{array}$ & $\begin{array}{l}\text { concordo } \\
(\%)\end{array}$ & $\begin{array}{c}\text { concordo } \\
\text { plenamente (\%) }\end{array}$ \\
\hline $\begin{array}{l}\text { 4.1 Considera-se que existe intenção dos } \\
\text { gestores públicos em adotar um sistema } \\
\text { de custos. }\end{array}$ & 50,7 & 38,9 & 1,5 & 7,4 & 1,5 \\
\hline $\begin{array}{l}\text { 4.2 Considera-se que existe interação entre } \\
\text { gestores e servidores para a adoção dos } \\
\text { sistemas de custos. }\end{array}$ & 55,2 & 6 & 28,3 & 3 & 7,5 \\
\hline $\begin{array}{l}4.3 \text { Considera que há intenção de } \\
\text { servidores à adoção dos sistemas de } \\
\text { custos. }\end{array}$ & 32,8 & 31,3 & 21 & 10,4 & 4,5 \\
\hline $\begin{array}{l}\text { 4.4 Considera-se que existe intenção dos } \\
\text { legisladores municipais para a adoção dos } \\
\text { sistemas de custos. }\end{array}$ & 43,3 & 35,8 & 14,9 & 6 & 0 \\
\hline $\begin{array}{l}4.5 \text { Considera-se que a instituição pretende } \\
\text { implantar técnicas de custeio nos próximos } \\
\text { anos. }\end{array}$ & 3 & 19,4 & 4,5 & 55,2 & 17,9 \\
\hline $\begin{array}{l}\text { 4.6 A prefeitura tem um cronograma de } \\
\text { implantação de sistema de custos. }\end{array}$ & 56,6 & 23,9 & 9 & 7,5 & 3 \\
\hline $\begin{array}{l}\text { 4.7 É possível implantar hoje um sistema } \\
\text { de controle de custos na prefeitura. }\end{array}$ & 31,3 & 13,4 & 43,3 & 9 & 3 \\
\hline $\begin{array}{l}\text { 4.8 A implantação de um sistema de custos } \\
\text { atenderia às necessidades operacionais da } \\
\text { instituição. }\end{array}$ & 0 & 7,5 & 13,4 & 76,1 & 3 \\
\hline
\end{tabular}

Fonte: Dados da pesquisa empírica.

De acordo com a Tabela 4, verifica-se a expressiva discordância acerca da intenção de adoção do sistema de custos por parte dos gestores em $89,6 \%$; servidores em $64,1 \%$; e legisladores em 79,1\%, segundo a concepção dos agentes públicos consultados. Destaca-se a proposição 4.7, na qual se constata o nível de indecisão de $43,3 \%$ sobre a possibilidade de implantação de sistema de custos na prefeitura. Mas, para $79,1 \%$ das opiniões, a referida implantação atenderia às necessidades operacionais.

O tópico 5 trata da concepção sobre sistemas de custos implantados. Nesse sentido, busca-se verificar aspectos como: controle de informação de custos; custos diretos, indiretos e método de custeio baseado em atividades (ABC) e sua relação com projetos e atividades, feedback, tomada de decisão, e geração de relatórios financeiros. Dito isso, expõe-se na Tabela 5 a percepção dos agentes públicos. 
Tabela 5

\section{Concepções sobre sistemas de custos implantados}

\begin{tabular}{|c|c|c|c|c|c|}
\hline Proposições do tópico 5 & $\begin{array}{c}\text { discordo } \\
\text { plenamente (\%) }\end{array}$ & $\begin{array}{l}\text { discordo } \\
(\%)\end{array}$ & $\begin{array}{l}\text { indeciso } \\
(\%)\end{array}$ & $\begin{array}{l}\text { concordo } \\
(\%)\end{array}$ & $\begin{array}{c}\text { concordo } \\
\text { plenamente (\%) }\end{array}$ \\
\hline $\begin{array}{l}\text { 5.1 Há controle de informações de custos } \\
\text { em planilhas e/ou sistemas independentes } \\
\text { não integrados. }\end{array}$ & 1,5 & 14,9 & 23,9 & 46,3 & 13,4 \\
\hline $\begin{array}{l}\text { 5.2 As informações de custos são } \\
\text { controladas por meio de sistema } \\
\text { integrado. }\end{array}$ & 38,8 & 22,4 & 28,3 & 4,5 & 6 \\
\hline $\begin{array}{l}5.3 \text { Os custos diretos são relacionados aos } \\
\text { projetos e/ou atividades. }\end{array}$ & 1,5 & 22,4 & 32,8 & 28,4 & 14,9 \\
\hline $\begin{array}{l}\text { 5.4 Os custos indiretos são relacionados } \\
\text { aos projetos e/ou atividades por } \\
\text { intermédio de alguma base de rateio. }\end{array}$ & 10,4 & 41,9 & 31,3 & 11,9 & 4,5 \\
\hline $\begin{array}{l}\text { 5.5 Os custos são relacionados a projetos } \\
\text { e atividades sob o uso do custeio por } \\
\text { Absorção. }\end{array}$ & 29,9 & 9 & 43,2 & 11,9 & 6 \\
\hline $\begin{array}{l}\text { 5.6 Os custos são relacionados aos } \\
\text { projetos e atividades sob o uso do Custeio } \\
\text { Baseado em Atividades (ABC). }\end{array}$ & 34,3 & 6 & 55,2 & 4,5 & 0 \\
\hline $\begin{array}{l}\text { 5.7 Os gestores recebem feedback quanto } \\
\text { aos controles de custos. }\end{array}$ & 9 & 43,2 & 22,4 & 20,9 & 4,5 \\
\hline $\begin{array}{l}\text { 5.8 As informações dos sistemas de custos } \\
\text { têm sido úteis para tomada de decisões } \\
\text { dos gestores e chefias de setor. }\end{array}$ & 23,9 & 13,4 & 19,4 & 37,3 & 6 \\
\hline $\begin{array}{l}\text { 5.9 Os sistemas de custos implantados } \\
\text { geram relatórios financeiros. }\end{array}$ & 10,4 & 19,4 & 26,9 & 40,3 & 3 \\
\hline
\end{tabular}

Fonte: Dados da pesquisa empírica.

A Tabela 5 permite visualizar que 59,7\% concordam com a existência de controle de informações de custos em planilhas e ou sistemas independentes não integrados nas prefeituras. Destacam-se os 43,3\% em relação aos custos diretos vinculados a projetos e atividades. Contrariamente apontam-se os 52,3\% discordantes na relação do custo indireto vinculados a projetos e atividades mediante utilização de base de rateio. Identificou-se indecisão de $43,2 \%$ sobre o uso do custeio por absorção e de $55,2 \%$ no uso do ABC. Ressalta-se a discordância de 52,2\% quanto ao feedback dos controles de custos; a concordância em $43,3 \%$ na utilidade da informação para a tomada de decisão e também a concordância de 43,3\% quanto aos sistemas de custos implantados gerarem relatórios financeiros.

No intuito de conhecer a concepção dos agentes públicos sobre sistemas operacionais, apresenta-se no tópico 6 um conjunto de proposição em que se verifica: integração dos sistemas operacionais; origem, geração e confiabilidade dos dados; e disponibilidade dos bancos de dados. Tais ponderações encontram-se dispostas na Tabela 6. 
Tabela 6

\section{Concepções sobre sistemas operacionais}

\begin{tabular}{|c|c|c|c|c|c|}
\hline Proposições do tópico 6 & $\begin{array}{c}\text { discordo } \\
\text { plenamente (\%) }\end{array}$ & $\begin{array}{l}\text { discordo } \\
(\%)\end{array}$ & $\begin{array}{l}\text { indeciso } \\
(\%)\end{array}$ & $\begin{array}{l}\text { concordo } \\
(\%)\end{array}$ & $\begin{array}{c}\text { concordo } \\
\text { plenamente (\%) }\end{array}$ \\
\hline $\begin{array}{l}\text { 6.1 Os sistemas operacionais são } \\
\text { integrados entre si, de forma a utilizar as } \\
\text { mesmas bases de dados. }\end{array}$ & 3 & 34,3 & 29,9 & 22.4 & 10,4 \\
\hline $\begin{array}{l}\text { 6.2 Os dados dos sistemas operacionais } \\
\text { originam-se de vários bancos de dados. }\end{array}$ & 1,5 & 13,4 & 19,4 & 62,7 & 3 \\
\hline $\begin{array}{l}\text { 6.3 Os dados disponíveis nos bancos de } \\
\text { dados são compatíveis e compartilhados } \\
\text { entre as áreas. }\end{array}$ & 6 & 46,3 & 16,4 & 17,9 & 13,4 \\
\hline $\begin{array}{l}\text { 6.4 Os dados disponíveis nos sistemas } \\
\text { operacionais apresentam muitos erros. }\end{array}$ & 9 & 20,9 & 34,3 & 22,4 & 13,4 \\
\hline $\begin{array}{l}\text { 6.5 Os dados disponíveis nos sistemas } \\
\text { operacionais são estáveis e não sofrem } \\
\text { variações com freqüência e podem, } \\
\text { portanto, ser considerados confiáveis. }\end{array}$ & 19,4 & 7,5 & 49,2 & 16,4 & 7,5 \\
\hline
\end{tabular}

Fonte: Dados da pesquisa empírica.

Conforme Tabela 6, constata-se equilíbrio no posicionamento assumido pelos agentes públicos em relação à utilização das mesmas bases de dados a partir de sistemas operacionais integrados. Também, na proposição 6.4, se observa equilíbrio de opinião no que trata da presença de erros nos dados disponíveis nos sistemas operacionais. Porém, contraditoriamente, na proposição 6.5 , enfatiza-se o nível de $49,2 \%$ que se declaram indecisos em relação à estabilidade e confiabilidade dos dados disponíveis nos sistemas operacionais. De forma complementar, aponta-se a concordância de $65,7 \%$ sobre a origem diversa dos dados e a discordância de 52,3\% na disponibilidade e compartilhamentos de dados entre as áreas.

Dito isso, encerram-se apontamentos e observações inerentes à análise descritiva dos dados. Seguem, no desenvolvimento deste estudo, inferências quanto à análise de correlação aplicada entre as proposições submetidas às considerações dos agentes públicos.

\subsection{Análise de correlação das proposições}

No intuito de relacionar o entendimento dos agentes públicos acerca das proposições investigativas referentes à importância da informação de custos, viabilidade e utilidade do sistema de custos, aplica-se o teste coeficiente de correlação de Spearman. E, assim, busca-se filtrar a correlação entre proposições comparativamente às respostas obtidas acerca dos níveis de percepção: discordo plenamente; discordo; indeciso; concordo; concordo plenamente. Executa-se correlação entre proposições com abordagem ao mesmo tópico, como forma de testar o entendimento dos agentes públicos às referidas proposições, as quais são apresentadas na Tabela 7. 
Tabela 7

\section{Correlação de Spearman e o nível de significância}

\begin{tabular}{lllc} 
& N & $\begin{array}{c}\text { Coeficiente } \\
\text { Spearman }\end{array}$ & $\begin{array}{c}\text { Significância } \\
\text { (1-tailed) }\end{array}$ \\
\hline Correlação entre as proposições 1.3 e 1.6 & 5 & $1,000 * *$ & 0,000 \\
\hline Correlação entre as proposições 1.4 e 1.5 & 5 & $0,900 *$ & 0,019 \\
\hline Correlação entre as proposições 1.7 e 1.8 & 5 & $-0,900 *$ & 0,019 \\
\hline Correlação entre as proposições 2.1 e 2.2 & 5 & $0,975 * *$ & 0,002 \\
\hline Correlação entre as proposições 3.1 e 3.6 & 5 & $0,872 *$ & 0,027 \\
\hline Correlação entre as proposições 4.1 e 4.3 & 5 & $0,821 *$ & 0,044 \\
\hline Correlação entre as proposições 4.1 e 4.4 & 5 & $0,821 *$ & 0,044 \\
\hline Correlação entre as proposições 4.1 e 4.6 & 5 & $0,821 *$ & 0,044 \\
\hline Correlação entre as proposições 4.4 e 4.6 & 5 & $1,000 * *$ & 0,000 \\
\hline Correlação entre as proposições 5.1 e 5.9 & 5 & $0,900 *$ & 0,019 \\
\hline Correlação entre as proposições 6.2 e 6.4 & 5 & $0,900 *$ & 0,019 \\
\hline
\end{tabular}

$\mathrm{N}$ : tamanho da amostra.

* A correlação é significante para o nível de 0,05\%.

** A correlação é significante para o nível de $0,01 \%$.

Fonte: Dados da pesquisa empírica.

Os resultados identificados mediante aplicação do coeficiente de Spearman apresentam a magnitude que varia entre -1 (correlação perfeita negativa) e +1 (correlação perfeita positiva), passando pelo valor 0 (ausência de correlação). Após a aplicação do referido coeficiente, cujos resultados encontram-se evidenciados na Tabela 7, apresentam-se as seguintes ponderações no que tange às correlações constatadas, a saber:

\begin{tabular}{|c|l|}
\hline $\begin{array}{c}\text { Correlação entre as } \\
\text { proposições 1.3 e 1.6 }\end{array}$ & $\begin{array}{l}\text { O teste de correlação aplicado às proposições 1.3 e 1.6 com resultado de 1,000 para } \\
\text { coeficiente de Spearman e para o nível de significância de 0,01\% remete a considerar } \\
\text { a correlação perfeita positiva, ou seja, a concordância na adoção de algum controle de } \\
\text { custos para o setor administrativo e de obras. }\end{array}$ \\
\hline $\begin{array}{c}\text { Correlação entre as } \\
\text { proposições 1.4 e 1.5 }\end{array}$ & $\begin{array}{l}\text { O resultado de 0,900 no coeficiente de Spearman e nível de significância de 0,019 torna } \\
\text { válida a correlação entre as proposições 1.4 e 1.5, no que trata da adoção de medidas de } \\
\text { controle de custos para a educação e saúde no município. }\end{array}$ \\
\hline $\begin{array}{c}\text { Correlação entre as } \\
\text { proposições 1.7 e 1.8 }\end{array}$ & $\begin{array}{l}\text { A correlação entre as proposições 1.7 e 1.8, com valor de 0,900 para o coeficiente de } \\
\text { Spearman e nível de significância de 0,019, remete a afinidade de percepção para se } \\
\text { adotar controle de custos em diversos setores combinado com a importância do esforço } \\
\text { da administração na adoção de sistema de custos. }\end{array}$ \\
\hline $\begin{array}{c}\text { Correlação entre as } \\
\text { proposições } \mathbf{2 . 1} \text { e } \mathbf{2 . 2}\end{array}$ & $\begin{array}{l}\text { O índice de correlação entre as proposições 2.1 e 2.2, cujo valor é 0,975 para o } \\
\text { coeficiente de Spearman e 0,002 para o nível de significância, indica forte afinidade } \\
\text { na concepção acerca da viabilidade orçamentária e financeira para a implantação de } \\
\text { sistemas de custos. }\end{array}$ \\
\hline $\begin{array}{c}\text { Correlação entre as } \\
\text { proposições 3.1 e 3.6 }\end{array}$ & $\begin{array}{l}\text { As proposições 3.1 e 3.6 encontram-se fortemente correlacionadas, conforme } \\
\text { coeficiente de Spearman de 0,875 e nível de significância de 0,027, em que relaciona a } \\
\text { indecisão referente a conhecer os fatores que influenciam custos combinado com a não } \\
\text { concordância sobre a existência de corpo técnico especializado em custos. }\end{array}$ \\
\hline
\end{tabular}




\begin{tabular}{|c|c|}
\hline $\begin{array}{l}\text { Correlação entre as } \\
\text { proposições } 4.1 \text { e } 4.3\end{array}$ & \multirow{3}{*}{$\begin{array}{l}\text { A proposição } 4.1 \text { ao ser correlacionada com as proposições 4.3; 4.4; e } 4.6 \text { apresentam } \\
\text { o índice de } 0,821 \text { no coeficiente de Spearman e nível de significância de } 0,044 \text {, o que } \\
\text { caracteriza uma correlação positiva acerca da discordância na intenção dos gestores, } \\
\text { servidores e legisladores adotarem um sistema de custos e a presença de um } \\
\text { cronograma para a implantação do sistema de custos. }\end{array}$} \\
\hline $\begin{array}{l}\text { Correlação entre as } \\
\text { proposições } 4.1 \text { e } 4.4\end{array}$ & \\
\hline $\begin{array}{l}\text { Correlação entre as } \\
\text { proposições } 4.1 \text { e } 4.6\end{array}$ & \\
\hline $\begin{array}{l}\text { Correlação entre as } \\
\text { proposições } 4.4 \text { e } 4.6\end{array}$ & $\begin{array}{l}\text { O valor do coeficiente de Spearman de 1,000 e nível de significância de } 0,01 \% \text {, remete } \\
\text { a considerar a forte correlação positiva entre as proposições } 4.4 \text { e } 4.6 \text {, referente a } \\
\text { discordância da intenção de legisladores municipais em adotar sistemas de custos } \\
\text { combinado com a discordância sobre a existência de um cronograma de implantação de } \\
\text { custos. }\end{array}$ \\
\hline $\begin{array}{l}\text { Correlação entre as } \\
\text { proposições } 5.1 \text { e } 5.9\end{array}$ & $\begin{array}{l}\text { Diante do coeficiente de 0,900 de correlação e nível de significância de } 0,019 \text {, entre } \\
\text { as proposições } 5.1 \text { e 5.9, constata-se a afinidade de concepção dos agentes públicos } \\
\text { na concordância no controle de informações de custos em planilhas e ou sistemas } \\
\text { independentes não integrados e a respectiva geração de relatórios financeiros. }\end{array}$ \\
\hline $\begin{array}{l}\text { Correlação entre as } \\
\text { proposições } 6.2 \text { e } 6.4\end{array}$ & $\begin{array}{l}\text { As proposições } 6.2 \text { e } 6.4 \text { apresentam coeficiente de Spearman de 0,900 e nível de } \\
\text { significância de } 0,019 \text {, ou seja, a correlação positiva quanto aos dados dos sistemas } \\
\text { operacionais que se originam de vários bancos de dados, e que os dados disponíveis nos } \\
\text { sistemas operacionais apresentam muitos erros. }\end{array}$ \\
\hline
\end{tabular}

Figura 2. Resultados referentes à correlação entre as proposições.

Fonte: Dados da pesquisa empírica.

Diante do exposto, fundamentado na aplicação da análise descritiva e do teste estatístico de correlação do coeficiente de Spearman, demonstra-se que a concepção do agente público tem frente à importância, viabilidade e utilidade do uso de um sistema de custos ainda é incipiente, embora o presente estudo constate a presença de um percentual significativo entre os agentes públicos consultados que assumem posição coerente ao concordar ou discordar de proposições que tratam de informação e controle de custos. Certamente, é positivo para o município que dispõe de agentes públicos com tal percepção no momento da obrigatoriedade de implantação do sistema de custos.

\section{Considerações Finais}

As atividades desenvolvidas por entes públicos, no caso, municípios, instiga a busca por informação em relação às práticas de gestão dos recursos públicos. No caso, afirma-se que o presente estudo alcançou o objetivo proposto, que é conhecer o nível de entendimento e de adoção quanto aos sistemas de custos por parte dos municípios do Paraná, mediante aplicação de survey. Logo, os resultados identificados não podem ser generalizados, pois se reportam exclusivamente à amostra consultada, cujos dados foram submetidos à aplicação de análise descritiva e do teste estatístico de correlação do coeficiente de Spearman.

De forma complementar, analisaram-se o nível de dificuldades de implantação, o grau de conhecimento acerca de sistemas de custos por parte destes profissionais e as noções de condições estruturais e financeiras. Os resultados demonstram a existência de limitações no conhecimento por parte dos agentes públicos, sobretudo, nos tópicos que tratam de viabilidade orçamentária e financeira da adoção de sistemas de custos; ambiente para o sistema de custos; sistemas de custos implantados; e sistemas operacionais. 
Destaca-se o viés de indecisão para as proposições a seguir: 44,7\% são indecisos quanto à existência de viabilidade orçamentária e financeira para a implantação de sistemas de custos após o ano de 2012; $61,2 \%$ em relação à instituição conhecem os fatores que influenciam o custo de seus projetos e atividades; $43,3 \%$ quanto à possibilidade de implantar hoje um sistema de controle de custos na prefeitura; $43,2 \%$ no que se refere aos custos relacionados a projetos e atividades sob o uso do custeio por absorção; $55,2 \%$ quando os custos são relacionados aos projetos e atividades sob o uso do ABC; 49,2\% indecisos em relação à proposição de que os dados disponíveis nos sistemas operacionais são estáveis e não sofrem variações com frequência e podem, portanto, ser considerados confiáveis.

Nada obsta ressaltar, conforme a Tabela 5, o retrato da concepção dos respondentes relativamente aos sistemas de custos, entre as municipalidades paranaenses. É de se notar que são reduzidos os índices de implantação efetiva desses sistemas, haja vista a concordância plena de existência de controle de custos por meio de planilhas e/ou sistemas, na ordem de 13,4\% (tópico 5.1), de que as informações de custos são controladas por meio de sistema integrado, na ordem de 6\% (tópico 5.2) e de que os sistemas de custos geram informações úteis para a tomada de decisão, no percentual de 6\% (tópico 5.8).

Por fim, salienta-se a relevância deste estudo, de cunho descritivo, por investigar aspectos inerentes a sistemas de custos e sua implantação nos municípios. Por se tratar de estudo fundamentado na concepção dos agentes públicos aos tópicos relacionados a sistema de custos, constata-se a incipiência do conhecimento acerca da importância, viabilidade e utilidade de um sistema de custos, embora as respostas obtidas nas proposições sobre informação e controle de custos tenham sido significativamente coerentes.

\section{Referências}

Boaventura, E.M. (2004) Metodologia da Pesquisa. São Paulo: Atlas.

Lei 4320/64, de 17 de março de 1964. (1964). Estatui normas gerais de direito financeiro para elaboração e controle dos orçamentos e balanços da União, Estados, Municípios e do Distrito Federal. Diário Oficial da República Federativa do Brasil, Brasília, DF, de 23/03/64.

Lei Complementar $n^{\circ}$ 101, de 04 de maio de 2000. (2000). Lei de Responsabilidade Fiscal. Estabelece normas de finanças públicas voltadas para a responsabilidade na gestão fiscal e dá outras providências. Diário Oficial da República Federativa do Brasil, Brasília, de 05/05/00.

Portaria MF no 184 de 25 de agosto de 2008. (2008) Dispõe sobre as diretrizes a serem observadas no setor público (pelos entes públicos) quanto aos procedimentos, práticas, elaboração e divulgação das demonstrações contábeis, de forma a torná-los convergentes com as Normas Internacionais de Contabilidade Aplicadas ao Setor Público. Diário Oficial da República Federativa do Brasil, Brasília, de 26/08/08.

Conselho Federal de Contabilidade. (2008). NBC T 16 Norma Brasileira de Contabilidade Aplicada ao Setor Público. NBC T 16.2 - Patrimônio e Sistemas Contábeis. Aprovada pela Resolução No 1.129 de 21/11/08. Publicada no Diário Oficial da União de 25/11/08.

Cooper, D.R. \& Schindler, P.S. (2003). Métodos de pesquisa em administração. (7. ed.). Porto Alegre: Bookmam.

Costa, J. G., Santos, A. C., Rodrigues, L. C., Barreto, M. L. \& Roberts, J. A. Tuberculose em Salvador: custos para o sistema de saúde e para as famílias. Revista de Saúde Pública. v. 39, n. 1, p. 122-128, 2005.

Dias, H.L., Gondrige, E.O., Clemente, A., Espejo, M.M.S.B. \& Voese, S.B. (2009). Custos no Setor Público: a Percepção dos Controladores de Recursos Públicos do Estado de Santa Catarina. Revista del Instituto Internacional de Costos, 5, 373-399.

Di Giacomo, W. (2005). O New Public Management no Canadá e a Gestão Pública Contemporânea. Interfaces Brasil/Canadá, 5, 155-170. 
Field, A. (2009). Descobrindo a estatística usando o SPSS. (2. ed.) Porto Alegre: Artmed.

Hood, C. (1989). Public administration and public policy: Intellectual challenges for the 1990s. Australian Journal of Public Administration, 48(4), 346-358.

Hood, C. (1995). Emerging Issues in Public Administration. Public Administration, 73(1), 165-183.

Martins, E. (2003). Contabilidade de Custos. (9. ed.) São Paulo: Atlas.

Meirelles, H.L. (2009). Direito Administrativo Brasileiro. (34. ed.) São Paulo: Malheiros Editores.

Instituto Paranaense de Desenvolvimento Econômico e Social, Ipardes. 2010. Recuperado em 21 abril, 2010 de $<$ http://www.ipardes.gov.br>.

Pereira, L.C.B. (1998). Reforma de Estado para a cidadania: a reforma gerencial brasileira na perspectiva internacional. São Paulo: ENAP, Editora.

Rezende, F., Cunha, A. \& Cardoso, R. Custos no Setor Público. Revista de Administração Pública, 44(4), 789-790.

Slomski, V. (2006). Manual de contabilidade pública: um enfoque na contabilidade municipal. (2. ed.) São Paulo: Atlas.

Silva, C.A.T. (2007). Custos no setor público. Brasília: Ed. Universidade de Brasília.

Sonfield. A., Kost. K., Gold. R. \& Finer, L.B. (2011). The public costs of births resulting from unintended pregnancies: national and state-level estimates. National Center for Biotechnology Information. Recuperado em 05 novembro, 2011 de http://www.ncbi.nlm.nih.gov.

Provimento $N^{\circ}$ 46/2001. (2001). Dispõe sobre a implantação do sistema de informações municipais e dá outras providências. Diário Oficial do Estado No. 6.122, de 30 nov. 2001. Curitiba, PR: Tribunal de Contas do Estado do Paraná - TCE-PR.

Turner, A.A., Woolley, M. \& Kingsley, T. (2007). Estimating the Public Costs and Benefits of Hope VI Investments: Methodological Report. The Urban Institute. Recuperado em 05 novembro, $2011 \mathrm{de}<$ http://www.urban.org>.

Wiemer, A.P.M. \& Ribeiro, D.C. (2004). Custos no Serviço Público. Anais do Congresso USP de Controladoria e Contabilidade. São Paulo, 4. 